\title{
How does Transvaginal Sonography Influence Surgical Strategies in Deep Endometriosis - The Role of the Classification System ENZIAN
}

\author{
Gernot Hudelist ${ }^{1 *}$ and Joerg Keckstein ${ }^{2}$ \\ ${ }^{1}$ Department of Gynaecology, Center for Endometriosis, Hospital St. John of God, Vienna, Austria \\ ${ }^{2}$ Endometriosis Centre - Dres. Keckstein Villach, Austria \\ ${ }^{\star}$ Corresponding author: Gernot Hudelist, MD, MSc, Hospital St. John of God, Johannes Gott Platz 1, 1020 Vienna, Austria
}

Received: September 01, 2020; Accepted: September 08, 2020; Published: September 15, 2020

In 1860, a Viennese pathologist named Carl Rokitansky first described histopathological features of adenomyosis by examination of histological sections of the uterus and the rectovaginal Space (RVS) [1]. First descriptions of radical surgical interventions reach back until 1903 when the German gynecologist H. Füth published a noteworthy case of a rectal shaving procedures including a radical hysterectomy procedure performed for a patient with extensive rectovaginal DE on the Lofot Islands, reporting on a "depressed vaginal vault and ulcerated surface the size of a half-a-crown" as well as a "....fixed mass the size of a fist stuck above the cervix just posterior to the uterus" [2].

Interestingly, the main surgical principles of radical resection of rectovaginal $\mathrm{DE}$ are similar to those described by the pioneer surgeons of the early 20th century. However, significant advances in minimally invasive surgical techniques have lead to the more widespread use of surgical treatment since then and surgical morbidity and mortality are - obviously - by far lower then a century ago. Today the treatment of endometriosis remains the same as it was when first described: the resection of all identified endometriotic lesions and preservation of reproductive function in patients wishing to conceive. However, besides minimal invasive approaches, the use of antibiotics and the armory of high-tech medicine it is first and foremost surgical skill and knowledge about the extent of the disease which will decide on optimal or suboptimal outcomes of surgical interventions. The lack of information about the extent of the disease before and during the procedure often leads to incomplete resections and pseudorecurrences. So how can knowledge on the extent of endometriosis, especially DE be increased before embarking on surgery?

The most cost effective, easy-at-hand and highly accurate noninvasive imaging method is transvaginal sonography (TVS), which is nowadays regarded as the first line diagnostic tool for patients with suspected endometriosis. Within this, 2 issues should be discussed: the accuracy of TVS for detection of DE and the need and applicability of a easy to use classification system that serves surgeon and sonographers to guide surgical therapies and plan interdisciplinary procedures.

Several meta-analysis have demonstrated that TVS accurately detects DE affecting the rectosigmoid, urinary bladder and uterosacral ligaments (USL`s) in experienced hands with - for example -overall, likelihood ratio pooled sensitivity, specificity, positive likelihood ratio (LR+) and negative likelihood ratio (LR-) for detecting DIE in the rectosigmoid up to $91 \%$ (95\%CI, 85-94\%), 97\% (95\%CI, 95-98\%), 33.0 (95\%CI, 18.6-58.6) and 0.10 (95\%CI, 0.06-0.16), respectively [3-5]. In addition, surgical risk factors such as low and deep rectal endometriosis, consequently low anastomotic height and therefore the elevated risk of anastomotic leakage (AL) following bowel resection may be correctly predicted by TVS [6].

Secondly, sonographers and surgeons need to speak the same language when describing $\mathrm{DE}$ with the aim to adequately stage $\mathrm{DE}$ preoperatively and facilitate optimal interdisciplinary surgery. Some attempts have been made to correlate the most widely used rASRM score with the results of TVS showing high accuracy for prediction of rASRM stages I-IV using TVS [7].

However, the rASRM score primarily describes the extent of intra-abdominal, tubo-ovarian adhesions and is of limited value when describing the extent and localization of severe DE. Extraperitoneal localization of the foci and/or severe adhesions may also obscure anatomical spaces and DE, which will only be correctly staged when surgery is expanded and hidden compartments and DE are exposed. As a result, another staging system named the ENZIAN classification has gained increasing acceptance by surgeons and diagnosticians since it is based on anatomical compartments and DE $[8,9]$. Recommended by several guidelines $[10,11]$ there is now also evidence that - in contrast to the rASRM score - DE described by the ENZIAN score does indeed significantly correlate with type and severity of symptoms in women with DE [12]. This knowledge opens up future new insights into the disease, which were not possible with the application of the rASRM classification. Furthermore, there is increasing evidence that the ENZIAN classification is also applicable to MRI and TVS underlining its use in surgical staging and diagnostic workup with surgical planning [13-17].

So how does TVS influence surgical therapy? The answer is simple - by detailed knowledge on the true extent and localization of the disease. Endometriosis surgery used to be determined primarily 
by decisions made during surgery. By using non-invasive tools such as TVS can now provide the surgeon with a detailed image of the localization and extent of DE, which is essential and makes complete and safe endometriosis surgery much easier.

Routinely performed and widespread use of non-invasive imaging with TVS can, as a consequence and in the ideal scenario, lead to triage of women with suspected endometriosis to a surgical "lowrisk" and "high risk" group. In the authors opinion, women with DE exhibiting colorectal, vaginal or ureteral involvement should - similar to oncological patients - be dealt as "high risk" patients and be treated by skilled and well-trained high-volume gynecological surgeons in tertiary referral centers with colorectal and urological surgeons in a team setting. This may increase optimal surgical outcomes and minimize severe complications [18]. TVS is the optimal tool to guide this referral strategy. The additional use of a generally applicable classification score such as the ENZIAN system has the potential to enable clinicians dealing with endometriosis to communicate with one common language, independent on the diagnostic technique or surgical treatment method. Bona diagnosis, bona curatio.

\section{References}

1. Rokitansky K (1860) Ueber Uterusdruesen-Neubildung. Zeitschrift der kaiserl königl Gesellschaft der Aerzte zu Wien 37: 578-581.

2. Hudelist G, Keckstein J, Wright JT (2009) The migrating adenomyoma: past views on the etiology of adenomyosis and endometriosis. Fertil Steril 92: 1536-1543. [crossref]

3. Hudelist G, English J, Thomas AE, Tinelli A, Singer CF, et al. (2011) Diagnostic accuracy of transvaginal ultrasound for non-invasive diagnosis of bowel endometriosis: systematic review and meta-analysis. Ultrasound Obstet Gynecol 37: 257-263. [crossref]

4. Guerriero S, Ajossa S, Orozco R, Perniciano M, Jurado M, et al. (2016) Accuracy of transvaginal ultrasound for diagnosis of deep endometriosis in the rectosigmoid: systematic review and meta-analysis. Ultrasound Obstet Gynecol 47: 281-289. [crossref]

5. Guerriero S, Ajossa S, Minguez JA, Jurado M, Mais V, et al. (2015) Accuracy of transvaginal ultrasound for diagnosis of deep endometriosis in uterosacral ligaments, rectovaginal septum, vagina and bladder: systematic review and metaanalysis. Ultrasound Obstet Gynecol 46: 534-545. [crossref]
6. Aas-Eng MK, Dauser B, Lieng M, Condous G, Hudelist G (2020) Transvaginal sonography accurately predicts lesion to anal verge distance in women with deep endometriosis of the rectosigmoid. Ultrasound Obstet Gynecol.

7. Leonardi M, Espada M, Choi S, Chou D, Chang T, et al. (2020) Transvaginal Ultrasound Can Accurately Predict the American Society of Reproductive Medicine Stage of Endometriosis Assigned at Laparoscopy. J Minim Invasive Gynecol 4650: 30117-30125. [crossref]

8. Tuttlies F, Keckstein J, Ulrich U, Possover M, Schweppe KW, et al. (2005) [ENZIANscore, a classification of deep infiltrating endometriosis]. Zentralbl Gynakol 127: 275281. [crossref]

9. Keckstein J, Ulrich U, Possover M, Schweppe KW (2003) ENZIAN-Klassifikation der tief infiltrierenden Endometriose. Zentralbl Gynäkol 125: 291.

10. Ulrich U, Buchweitz O, Greb R, Keckstein J, von Leffern I, et al. (2013) Interdisciplinary S2k Guidelines for the Diagnosis and Treatment of Endometriosis. Geburtshilfe Frauenheilkd 73: 890-898.

11. Working group of Esge E, Wes, Keckstein J, Becker CM, Canis M, et al. (2020) Recommendations for the surgical treatment of endometriosis. Part 2: deep endometriosis. Human Reproduction Open 2020: 002. [crossref]

12. Montanari E, Dauser B, Keckstein J, Kirchner E, Nemeth Z, et al. (2019) Association between disease extent and pain symptoms in patients with deep infiltrating endometriosis. Reprod Biomed Online 39: 845-851. [crossref]

13. Burla L, Scheiner D, Samartzis EP, Seidel S, Eberhard M, et al. (2019) The ENZIAN score as a preoperative MRI-based classification instrument for deep infiltrating endometriosis. Arch Gynecol Obstet 300: 109-116. [crossref]

14. Di Paola V, Manfredi R, Castelli F, Negrelli R, Mehrabi S, et al. (2015) Detection and localization of deep endometriosis by means of MRI and correlation with the ENZIAN score. Eur J Radiol 84: 568-574. [crossref]

15. Haas D, Chvatal R, Habelsberger A, Schimetta W, Wayand W, et al. (2013) Preoperative planning of surgery for deeply infiltrating endometriosis using the ENZIAN classification. Eur J Obstet Gynecol Reprod Biol 166: 99-103. [crossref]

16. Hudelist G, Montanari E, Dauser B, Nemeth Z, Keckstein J (2020) Comparison between sonography-based and surgical extent of deep endometriosis (DE) using the Enzian classification, Abstract, Meeting of the Stiftung Endometrioseforschung, Weissensee.

17. Thomassin-Naggara I, Lamrabet S, Crestani A, Bekhouche A, Wahab CA, et al. (2020) Magnetic resonance imaging classification of deep pelvic endometriosis: description and impact on surgical management. Hum Reprod 35: 1589-1600.

18. Bendifallah S, Roman H, Rubod C, Leguevaque P, Watrelot A, et al. (2018) Impact of hospital and surgeon case volume on morbidity in colorectal endometriosis management: a plea to define criteria for expert centers. Surg Endosc 32: 2003-2011. [crossref] 